\title{
An inventory model with a new credit drift: Flexible trade credit policy
}

\author{
Ankit Prakash Tyagi*
}

DBS (PG) College, Dehradun, India

\begin{tabular}{l}
\hline C H R O N I C L E \\
\hline Article history: \\
Received April 222015 \\
Received in Revised Format \\
July 232015 \\
Accepted July 232015 \\
Available online \\
July 302015 \\
\hline Keywords: \\
Inventory \\
EOQ \\
Flexible Trade Credit Policy \\
Permissible delay \\
Trade credit
\end{tabular}

\begin{abstract}
A B S T R A C T
In most of the published articles dealing with optimal order quantity model under permissible delay in payments, it is assumed that the supplier only put forwards fully permissible delay in payments if retailer ordered a bulky sufficient quantity otherwise permissible delay in payments would not be permitted. Practically, in competitive market environments and recession phases of business, every supplier wants to attract more retailers by the help of providing good facilities for trading. Necessity of order quantity may put a negative pressure on supplier's demand. So, within the economic order quantity (EOQ) framework the main purpose of this paper is to broaden this extreme case by introducing a new credit policy, Flexible Trade Credit Policy (FTCP), for supplier which can help him provide more free space of trading to retailers. This policy, after adopting by suppliers, not only provides attractive trading environments for retailers but also enhances the demand of supplier due to the large number of new retailers. Here in, under this policy, an inventory system is investigated as a cost minimization problem to establish the retailer's optimal inventory cycle time and optimal order quantity. Three theorems are established to describe and to lighten optimal replenishment policies for the retailer. Finally, numerical examples are considered to illustrate all these theorems and managerial insights are given based on considered numerical examples.
\end{abstract}

\section{Introduction}

The EOQ (economic order quantity) model has been widely working as a decision-making tool for managers to control inventory where payment patterns have changed under permit of delaying. Generally, most of the EOQ models, it is understood that the retailers have to pay for the items as soon as the items are received. In practice, the supplier intends to raise his product's demand and so he will offer a delay period, namely, the trade credit period: Before the end of the trade credit period, retailer can sell the goods to accumulate revenue and earn interest. On the other hand, a higher interest is charged if the payment is not settled by the end of the trade credit period. Therefore, it makes economic intellect for retailer to postponement the settlement of the replenishment account till the last moment of the permissible period permitted by the supplier.

* Corresponding author.

E-mail: ankitprakashtyagi88@gmail.com (A. P. Tyagi)

(c) 2016 Growing Science Ltd. All rights reserved.

doi: 10.5267/j.ijiec.2015.7.005 
Numerous papers discussing the consequence of supplier's credit policies on the optimal order quantity within the economic order quantity skeleton have appeared in the literatures that study inventory problems under varying conditions. It is easily observed that the supplier's credit policy fall into two categories: one, where credit terms are not depended on the order quantity and second, where credit terms are linked to the order quantity.

Some of the prominent papers of first category have been discussed as; Goyal (1985) recognized a solo item inventory model for decisive EOQ approach whereas the supplier offers the retailer the possibility to delay his payment within a fixed time period. Chung (1998) discussed the exploration of the optimal solution for the problem explored by Goyal (1985). Aggarwal and Jaggi (1995) measured the inventory model with an exponential deterioration rate under the stipulation of permissible delay in payments. Jamal et al. (2000) derived a model where the retailer can pay the wholesaler either at the end of the credit period or later, incurring interest charges on the owing balances for the behind schedule period. They urbanized a retailer's policy for the optimal cycle and payment times for a retailer in a deterioratingitem inventory scenario, in which a wholesaler allows a specified credit period for payment without fine. Teng (2002) specified that the selling price is not equal to the purchasing price to modify Goyal's model (1985). The important finding from Teng's study (2002) is that it makes economic logic for a wellrecognized retailer to order small lot sizes and to take more frequently the benefits of the permissible delay in payments.

Chung and Huang (2003) developed Goyal (1985) to think about the case that the units are replenished at a finite rate under permissible delay in payments and urbanized an efficient solution-finding procedure to determine the retailer's optimal ordering policy. Huang and Chung (2003) developed Goyal's model (1985) to talk about the replenishment and payment policies to minimize the annual total average cost under cash discount and payment delay from the retailer's point of view. They understood that the supplier could adopt a cash discount policy to magnetize retailer to pay the full payment of the amount of purchasing at a prior time as a means to condense the collection period. Abad and Jaggi (2003) formulated models of seller-buyer affiliation. They provided dealings for finding the best policies for both seller and buyer under non-cooperative and cooperative relationship respectively. Huang (2004) extended Chung and Huang's model (2003), in allowing the retailer adopts different imbursement policy and finding differences between units acquire and selling price, and developed a well-organized solutionfinding procedure to conclude the retailer's optimal cycle time and optimal order quantity.

In order to move towards the second category of supplier's credit policy, Chung and Liao (2004) determined EOQ problem for exponentially deteriorating items under permissible delay in payment depending on the ordering quantity and provided an efficient solution-finding procedure to determine the retailer's optimal ordering policy. Chang (2004) extended the work of Chung and Liao (2004) by taking into account inflation and finite time horizon.

Chung et al. (2005) investigated the optimal inventory policies under permissible delay in payment depending on the ordering quantity. Huang (2007) represented an EOQ model under conditionally permissible delay in payments. The main purpose of this paper is to investigate the retailer's optimal replenishment policy under permissible delay in payments. Goyal et al. (2007) provided model for optimal ordering policies when the supplier provides a progressive interest scheme. Jaggi et al. (2008) provided an observation to incorporate that the supplier would offer a fixed credit period to the retailer but the retailer in turn would not offer any credit period to its customers. In this paper, they incorporated the concept of credit-linked demand and developed a new inventory model under two levels of trade credit policy to reflect the real-life situations. An easy-to-use algorithm was developed to determine the optimal credit as well as replenishment policy jointly for the retailer. Sana and Chaudhuri (2008) studied a deterministic EOQ model with delays in payments and price-discount offers to model the retailer's profit-maximizing strategy when confronted with supplier's trade tender of credit and price-discount on the purchase of merchandise. Liao and Chung (2009) provided the optimal ordering policy of the EOQ 
model under the trade credit depending on the ordering quantity from the DCF approach. Chang et al. (2009) incorporated the concept of vender-buyer integration and order-size-dependent trade credit. They presented a stylized model to determine the optimal strategy for an integrated vender buyer inventory system under the condition of trade credit linked to the order quantity. Ouyang et al. (2009) generalized the Goyal (1985) model by incorporating real world's aspects like the retailer's selling price per unit is significantly higher than unit purchase price, interest rate charged by a bank is not necessarily higher than the retailer's investment return rate, many items such as fruits and vegetables deteriorate continuously and the supplier may offer a partial permissible delay in payments even if the order quantity is less than a sufficient quantity.

Kreng and Tan (2010) determined the optimal replenishment decisions under two levels of trade credit policy depending on the order quantity. Huang et al. (2010) studied an integrated vendor-buyer inventory model with order-processing cost reduction and permissible delay in payments. Chen and Kang (2010) investigated integrated inventory models considering the two-level trade credit policy and a pricenegotiation scheme. They developed in this paper the integrated inventory models with permissible delay in payment, in which customers' demand is sensitive to the buyer's price. A simple recursive solution procedure was proposed for the integrated models to determine the buyer's optimal pricing and production/order strategy.

Chung and Liao (2011) simplified solution algorithm for an integrated supplier-buyer inventory model with two-part trade credit in a supply chain system. In this paper they extended the paper of Ho et al. (2008) which was devoted to optimal pricing, shipment and payment policy for an integrated supplierbuyer inventory model with two-part trade credit. Zhou et al. (2012) presented an uncooperative order model for items with trade credit, inventory-dependent demand and limited displayed-shelf space. Seifert et al. (2013) presented a review of trade credit literature and discussed conflicting study outcomes. Zhou (2013)'s paper dealt two level of trade credit. And, in this paper the retailer may pay any fraction of the purchase cost within the short permissible delay period and receives a cash discount and then the rest is paid within the long permissible delay period. However, both categories of commerce with EOQ in the presence of the permissible delay in payment assumed that the supplier only offers fully permissible impediment in payment if the retailer orders a sufficient quantity. Otherwise, permissible delay in payment would not be tolerable.

This policy of supplier is generally used in stimulating demand from the retailer. In global competitive business environment, this policy is not practical and possesses an extreme case. So, to relax this intense case, it is needed to introduce a new credit policy (FTCP) that can be adopted by supplier to develop his demand. In this policy supplier provides a time limit to retailer who does not order sufficiently large quantity to trade without making any initial payment. After this time limit, retailer has to make payment with a few more interest within the period between the end of time limit and account settling time.

In this policy, retailer has not to pay any kind of payment at first point and extra charge will be applied for the period between first point and credit period ending point. Therefore, this length of time scale between first point and account settling time will play key role as: Increasing this time duration by placing first point towards starting point of trade will increase the revenue of supplier with extra charge; on the other hand decreasing this time duration by placing first point towards ending point of credit period will increase the order size of retailers by grabbing the opportunity of reduction cost and accumulating revenue at the cost of small extra charge.

It is important, because, to compete his competitor, the supplier can relax the extreme case to offer the retailer full permissible delay in payment under the new flexible trade credit policy rather than without permissible delay in payment when the order quantity is smaller than a predetermined quantity. By this policy to boost up his demand in recession, supplier can attract those retailers also who cannot place sufficient quantity to use credit facilities due to negative influences of quantity bench marks of orders. 
The retailer must pay his account and the payment with extra interest from the fixed point is settled by the end of the trade credit period to enjoy the full permissible delay.

From the view point of the supplier's marketing policy, the supplier can use the length of the fixed point under the flexible trade credit policy to agilely control the effect of stimulating the demand from the retailer who does not order a sufficient quantity. On the other hand, retailer has the opportunity to enjoy the full permissible delay period without restriction of placing the sufficient order quantity after paying small extra interest charge. This view point is a realistic, novel one and never mentioned before in this research field, that's why the focus of the present study forms.

Under these conditions, this study create a model for retailer's inventory system as a cost minimization problem to determine the retailer's optimal inventory cycle time and optimal order quantity. Three theorems are established to describe the optimal replenishment policy for the retailer under the more general framework. Finally, numerically examples are given to illustrate all these theorems.

\section{Model formulation and the convexity}

In this section, the present study develops a retailer's inventory model under a flexible trade policy. The following notation and assumptions are used throughout this paper.

\subsection{Notation}

D demand rate per year

A ordering cost per order

W quantity at which the fully delay payments permitted per order

$c \quad$ unit purchasing price

$s \quad$ unit selling price

$h \quad$ unit stock holding cost per year excluding interest charges

$I_{e} \quad$ interest earned per \$ per year

$I_{k} \quad$ interest charged per $\$$ in stocks per year

$I_{k}+I_{p} \quad$ interest charged per $\$$ in stocks per remaining period of credit period when the order quantity is smaller than $W$

$N \quad$ the length of the trade credit period, in years

$M \quad$ the length in the credit period fixed by supplier when the order quantity is less than $W$

$T \quad$ the length of the cycle time, in years

$Q \quad$ the order quantity

$\operatorname{TRC}(T)$ the annual total relevant cost, which is a function of $T$

$T^{*} \quad$ the optimal cycle time of $\operatorname{TRC}(T)$

$Q^{*} \quad$ the optimal order quantity $=D T^{*}$

\subsection{Assumptions}

(1) Replenishments are instantaneous.

(2) Demand rate, $D$ is known and constant.

(3) Shortages are not allowed.

(4) The inventory system involves only one type of inventory.

(5) Time horizon is infinite.

(6) If $T \geq N$, the order quantity is larger than a sufficient quantity $W$, the supplier will offer credit period $N$. Otherwise, the supplier applies a flexible credit policy like as: the supplier fixes a point $M$ in credit period $N$. In this situation, the retailer has to pay an 
interest with rate $\left(I_{k}+I_{p}\right)$ on items sold from a fixed point $M$ by the end of the credit period $N$.

(7) If $T<N$, the order quantity is smaller than a sufficient quantity $W$, the retailer has to pay an interest with rate $\left(I_{k}+I_{p}\right)$ on the items sold from the fixed point $M$ to $T$ and purchasing cost from $T$ to $N$.

(8) In both the situations, when ordered less and when ordered a sufficient quantity, the retailer can accumulate revenue and earn interest up to settling the account at $N$ with rate $I_{e}$

(9) $I_{k} \geq I_{e} \geq I_{p}$ and $s \geq c$.

\subsection{The model}

The annual total relevant cost consists of the following elements. There are three cases to occur: (1) $W / D \leq M$; (2) $M<W / D \leq N$; (3) $N<W / D$.

Case (1) Suppose that $W / D \leq M$

(1) Annual ordering cost $=\frac{A}{T}$.

(2) Annual stock holding cost excluding interest charges $=\frac{D T h}{2}$.

(3) From assumptions Eq, (6) and Eq. (7), there are three sub-cases in terms of annual opportunity cost of the capital.

(i) $M \leq T$.

The annual opportunity cost of capital $=-\left[s I_{e} \frac{D T^{2}}{2}+s I_{e} D T(N-T)\right] / T$.

(ii) $W / D \leq T \leq M$.

The annual opportunity cost of capital $=-\left[s I_{e} \frac{D T^{2}}{2}+s I_{e} D T(N-T)\right] / T$.

(iii) $0<T<W / D$, as shown in Fig. 1. The annual opportunity cost of capital $=\left[c D T\left(I_{k}+I_{p}\right)(N-M)-s I_{e} \frac{D T^{2}}{2}-s I_{e} D T(N-T)\right] / T$.

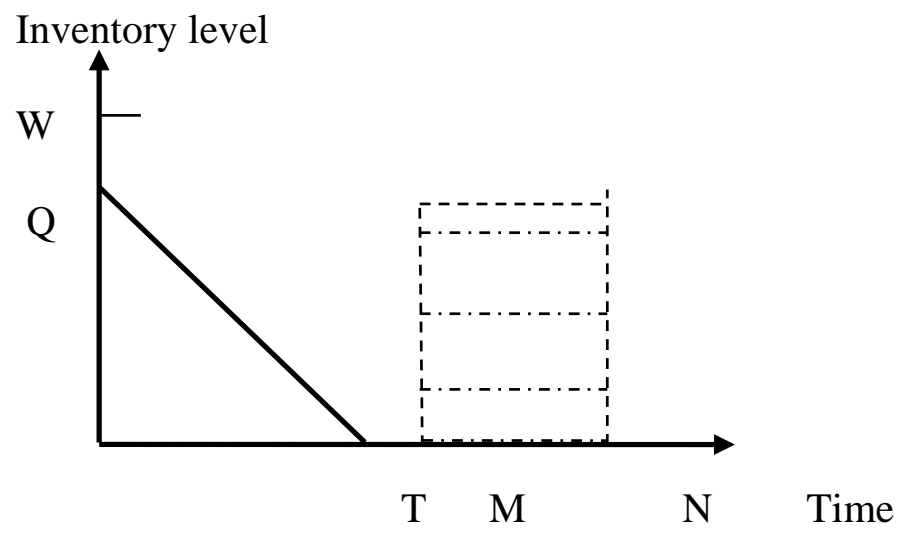

Fig. 1. The inventory level and the total saved amount of interest payable when $0<T<W / D$ From the above conditions, the annual total relevant cost for the retailer can be expressed as 
$\operatorname{TRC}(T)=$ Ordering cost + stock-holding cost + opportunity cost of capital .

$\operatorname{TRC}(T)=\left\{\begin{array}{c}T R C_{1}(T), \quad \text { if } M \leq T, \quad \text { (a) } \\ T R C_{2}(T), \quad \text { if } W / D \leq T \leq M, \quad \text { (b) } \\ T R C_{3}(T), \quad \text { if } 0<T<W / D, \quad \text { (c) }\end{array}\right.$

where

$T R C_{1}(T)=\frac{A}{T}+\frac{D T h}{2}-\frac{s I_{e} D T\left(N-\frac{T}{2}\right)}{T}$

$T R C_{2}(T)=\frac{A}{T}+\frac{D T h}{2}-\frac{s I_{e} D T\left(N-\frac{T}{2}\right)}{T}$

and

$T R C_{3}(T)=\frac{A}{T}+\frac{D T h}{2}+\frac{c D T\left(I_{k}+I_{p}\right)(N-M)}{T}-\frac{s I_{e} D T\left(N-\frac{T}{2}\right)}{T}$

Since $T R C_{1}(M)=T R C_{2}(M)$ and $T R C_{2}(W / D) \leq T R C_{3}(W / D), \quad T R C(T)$ is continuous except at $T=W / D$. Furthermore, we have $T R C_{3}(T)>T R C_{2}(T)$ for all $T>0$. Eqs. (2)- (3) yield

$$
\begin{aligned}
& T R C_{1}^{\prime}(T)=-\frac{A}{T^{2}}+\frac{D\left(h+s I_{e}\right)}{2} \\
& T R C_{1}^{\prime \prime}(T)=\frac{2 A}{T^{3}}>0 \\
& T R C_{2}^{\prime}(T)=-\frac{A}{T^{2}}+\frac{D\left(h+s I_{e}\right)}{2} \\
& T R C_{2}^{\prime \prime}(T)=\frac{2 A}{T^{3}}>0 \\
& T R C_{3}^{\prime}(T)=-\frac{A}{T^{2}}+\frac{D\left(h+s I_{e}\right)}{2} \\
& T R C_{3}^{\prime \prime}(T)=\frac{2 A}{T^{3}}>0
\end{aligned}
$$

Eq. (6), Eq. (8) and Eq. (10) imply that $T R C_{1}(T), T R C_{2}(T)$ and $T R C_{3}(T)$ are convex on $T>0$. Moreover, we have $T R C_{1}^{\prime}(T)=T R C_{2}^{\prime}(T)=T R C_{3}^{\prime}(T)$.

Case (2) Suppose that $M<W / D \leq N$

If $M<W / D \leq N$, Eqs. (1(a)-(c)) will be modified as

$$
\operatorname{TRC}(T)=\left\{\begin{array}{c}
T R C_{4}(T), \quad \text { if } N \leq T, \quad \text { (a) } \\
T R C_{1}(T), \quad \text { if } W / D \leq T<N, \quad \text { (b) } \\
T R C_{5}(T), \quad \text { if } M \leq T<W / D, \quad \text { (c) } \\
T R C_{3}(T), \quad \text { if } 0<T<M \quad \text { (d) }
\end{array}\right.
$$


when $M<W / D \leq N$, the annual total relevant cost, $T R C_{4}(T), T R C_{5}(T)$, consist of the following elements:

(1) Annual ordering $\operatorname{cost}=\frac{A}{T}$.

(2) Annual stock holding cost excluding interest charges $=\frac{D T h}{2}$.

(3) From assumptions (6) and (7), there are two sub-cases in terms of annual opportunity cost of the capital.

(i) $N \leq T$.

The annual opportunity cost of capital $=\left[c I_{k} \frac{D(T-N)^{2}}{2}-s I_{e} \frac{D N^{2}}{2}\right] / T$.

(ii) $M \leq T<W / D$, as shown in Fig. 2 .

The annual opportunity cost of capital

$$
=\left[c D\left(I_{k}+I_{p}\right) \frac{(T-M)^{2}}{2}+c D T\left(I_{k}+I_{p}\right)(N-T)-s I_{e} \frac{D T^{2}}{2}-s I_{e} D T(N-T)\right] / T \text {. }
$$

Combining the above conditions, we get

$$
\operatorname{TRC}_{4}(T)=\frac{A}{T}+\frac{D T h}{2}+\frac{c I_{k} D(T-N)^{2}}{2 T}-\frac{s I_{e} D N^{2}}{2 T}
$$

and

$$
T R C_{5}(T)=\frac{A}{T}+\frac{D T h}{2}+\frac{c\left(I_{k}+I_{p}\right) D(T-M)^{2}}{2 T}+\frac{c\left(I_{k}+I_{p}\right) D T(N-T)}{T}-\frac{s I_{e} D T\left(N-\frac{T}{2}\right)}{T}
$$

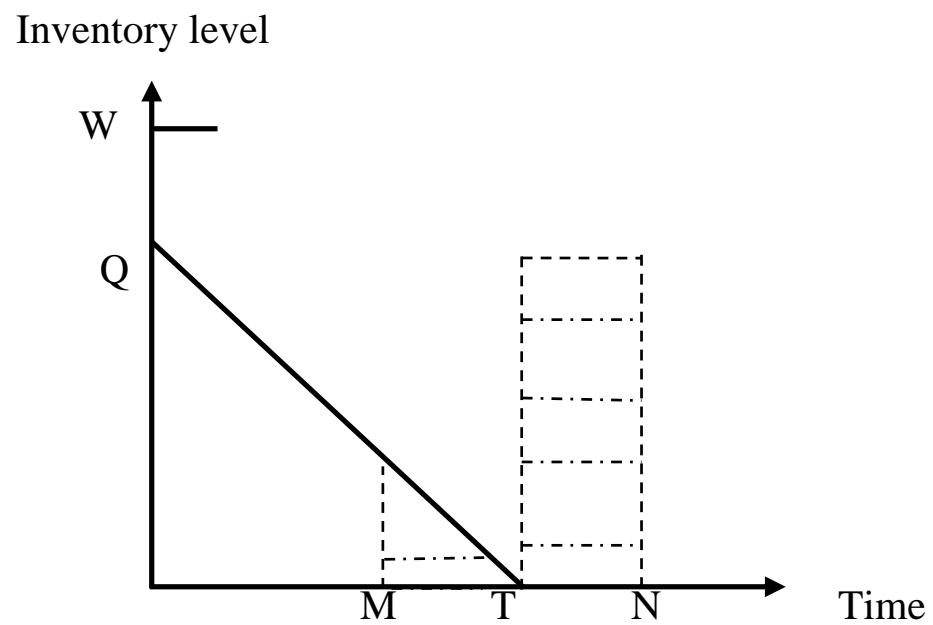

Fig. 2. The inventory level and the total saved amount of interest payable when $M \leq T<W / D$ Since $T R C_{4}(N)=T R C_{1}(N), \quad T R C_{1}(W / D) \leq T R C_{5}(W / D)$ and $T R C_{5}(M)=T R C_{3}(M), \quad T R C(T)$ is continuous except at $T=W / D$. Furthermore, we have $T R C_{5}(T) \geq T R C_{1}(T)$ for all $T>0$. Eqs. (12-13) yield

$$
\begin{aligned}
& T R C_{4}^{\prime}(T)=-\frac{\left[2 A+D N^{2}\left(c I_{k}-s I_{e}\right)\right]}{2 T^{2}}+\frac{D\left(h+c I_{k}\right)}{2} \\
& T R C_{4}^{\prime \prime}(T)=\frac{2 A+D N^{2}\left(c I_{k}-s I_{e}\right)}{2 T^{3}}>0
\end{aligned}
$$


$T R C_{5}^{\prime}(T)=-\frac{A}{T^{2}}+\frac{D h}{2}-\frac{c D\left(I_{k}+I_{p}\right)\left(T^{2}+M^{2}\right)}{2 T^{2}}+\frac{s I_{e} D}{2}$

$T R C_{5}^{\prime \prime}=\frac{2 A}{T^{3}}+\frac{c\left(I_{k}+I_{p}\right) D M^{2}}{T^{3}}>0$

Eq. (14) and Eq. (16) imply that $T R C_{4}(T)$ and $T R C_{5}(T)$ are convex on $T>0$. We have $T R C_{1}^{\prime}(N)=T R C_{4}^{\prime}(N), T R C_{1}^{\prime}(W / D) \neq T R C_{5}^{\prime}(W / D)$ and $T R C_{5}^{\prime}(M) \neq T R C_{3}^{\prime}(M)$.

Case (3) Suppose that $N<W / D$

If $N<W / D$, Eqs. (1(a)-(c)) and (11(a)-(d)) will be modified as

$$
\operatorname{TRC}(T)=\left\{\begin{array}{cc}
T R C_{4}(T), & \text { if } W / D \leq T \\
T R C_{6}(T), & \text { if } N \leq T<W / D \quad \text { (a) } \\
T R C_{5}(T), & \text { if } 0<T<N \quad \text { (c) }
\end{array}\right.
$$

when $N<W / D$, the annual total relevant cost, $T R C_{6}(T)$, consist of the following elements:

Inventory level

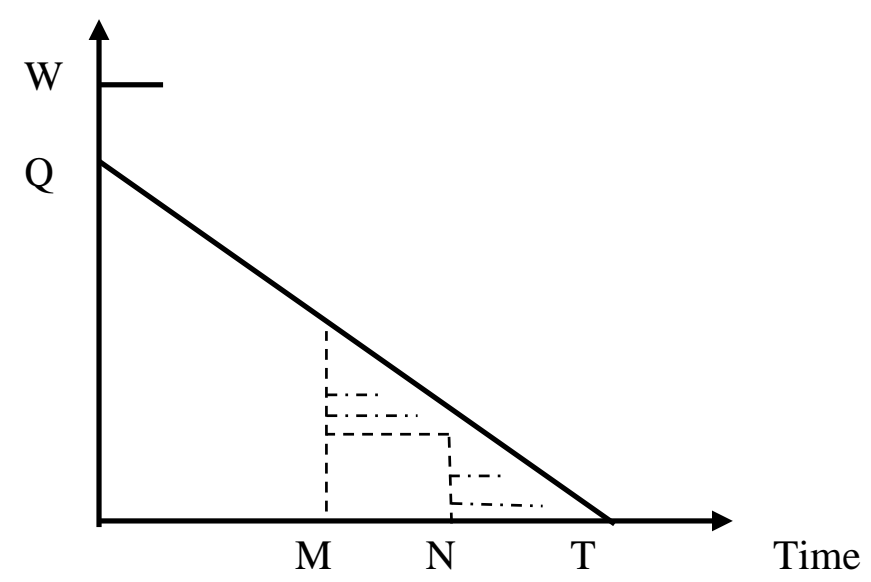

Fig. 3.The inventory level and the total saved amount of interest payable when $N \leq T<W / D$

(1) Annual ordering cost $=\frac{A}{T}$.

(2) Annual stock holding cost excluding interest charges $=\frac{D T h}{2}$.

(3) $N \leq T<W / D$

According to assumption (6) and (7), the annual opportunity cost of capital (as shown in Fig. 3)

$$
=\left[c D\left(I_{k}+I_{p}\right) \frac{(N-M)^{2}}{2}+c D I_{k} \frac{(T-N)^{2}}{2}-s I_{e} \frac{D N^{2}}{2}\right] / T .
$$

Combining the above conditions, we get

$$
T R C_{6}(T)=\frac{A}{T}+\frac{D T h}{2}+\frac{c D\left(I_{k}+I_{p}\right)(N-M)^{2}}{2 T}+\frac{c D I_{k}(T-N)^{2}}{2 T}-\frac{s I_{e} D N^{2}}{2 T}
$$

Since $T R C_{5}(N)=T R C_{6}(N)$ and $T R C_{6}(W / D)>T R C_{4}(W / D), T R C(T)$ is continuous except at $T=W / D$. Furthermore, we have $T R C_{6}(T)>T R C_{4}(T)$ for all $T>0$. Eq. (19) yields 


$$
T R C_{6}^{\prime}(T)=\frac{-\left[2 A+D N^{2}\left(c I_{k}-s I_{e}\right)+c D\left(I_{k}+I_{p}\right)(N-M)^{2}\right]}{2 T^{2}}+\frac{D\left(h+c I_{k}\right)}{2},
$$

$$
T R C_{6}^{\prime \prime}(T)=\frac{\left[2 A+D N^{2}\left(c I_{k}-s I_{e}\right)+c D\left(I_{k}+I_{p}\right)(N-M)^{2}\right]}{T^{3}}>0 .
$$

Eq. (21) implies that $T R C_{6}(T)$ is convex on $T>0$. Moreover, we have $T R C_{4}^{\prime}(W / D) \neq T R C_{6}^{\prime}(W / D)$ and $T R C_{6}^{\prime}(N) \neq T R C_{5}^{\prime}(N)$.

\section{Decision rules for the optimal cycle time $T^{*}$}

In this section, the present study exhibits the determination of the optimal cycle time for three cases above, under the condition of minimizing annual total relevant costs.

\subsection{Decision rule of the optimal cycle time when $W / D \leq M$}

From Eq. (5), Eq. (7) and Eq. (9), find $T_{i}^{*}$ such that $T R C_{i}^{\prime}\left(T_{i}^{*}\right)=0$ for each $i=1,2,3$. Then, we can obtain

$$
T_{i}^{*}=\sqrt{\frac{2 A}{D\left(h+s I_{e}\right)}}
$$

Eq. (22) gives that the optimal value $T^{*}$ for the case when $M \leq T$ so that $M \leq T_{1}^{*}$. Substituting Eq. (22) into $M \leq T_{1}^{*}$, then we can obtain that

$T_{1}^{*} \geq M$, if and only if $-2 A+D M^{2}\left(h+s I_{e}\right) \leq 0$.

Likewise, Eq. (22) gives that the optimal value $T^{*}$ for the case when $W / D \leq T \leq M$ so that $W / D \leq T_{2}^{*} \leq M$. Substituting Eq. (22) into $W / D \leq T_{2}^{*} \leq M$, we can obtain that

$T_{2}^{*} \geq M$, if and only if $-2 A+D M^{2}\left(h+s I_{e}\right) \geq 0$

and

$$
T_{2}^{*} \geq W / D \text {, if and only if }-2 A+\frac{M^{2}}{D}\left(h+s I_{e}\right) \leq 0 .
$$

Finally, Eq. (22) gives that the optimal value $T^{*}$ for the case when, $T<W / D$ so that $T_{3}^{*}<W / D$. Substituting Eq. (22) into $T_{3}^{*}<W / D$, when we can obtain that

$$
T_{3}^{*}<W / D \text {, if and only if }-2 A+\frac{W^{2}}{D}\left(h+s I_{e}\right)>0 \text {. }
$$

Furthermore, to simplify, we let

$$
\begin{aligned}
& \Delta_{1}=-2 A+D M^{2}\left(h+s I_{e}\right) \\
& \Delta_{2}=-2 A+\frac{W^{2}}{D}\left(h+s I_{e}\right)
\end{aligned}
$$

Eqs. (23-24) imply that $\Delta_{1} \geq \Delta_{2}$. In addition, we know that $T R C_{3}(T) \geq T R C_{2}(T)=T R C_{1}(T)$ for all $T>0$ from Eqs.(2-3). From above arguments, we can summarize the above results in Theorem 1.

Theorem1. Suppose that $W / D \leq M$, then

(A) If $\Delta_{1}<0$ and $\Delta_{2}<0$, then $\operatorname{TRC}\left(T^{*}\right)=T R C_{1}\left(T_{1}^{*}\right)$ and $T^{*}=T_{1}^{*}$. 
(B) If $\Delta_{1} \geq 0$ and $\Delta_{2}<0$, then $T R C\left(T^{*}\right)=T R C_{2}\left(T_{2}^{*}\right)$ and $T^{*}=T_{2}^{*}$.

(C) If $\Delta_{1} \geq 0$ and $\Delta_{2} \geq 0$, then $\operatorname{TRC}\left(T^{*}\right)=T R C_{3}\left(T_{3}^{*}\right)$ and $T^{*}=T_{3}^{*}$.

3.2. Decision rule of the optimal cycle time when $M<W / D \leq N$

If $M<W / D \leq N$, from Eqs. (11(a)-(d)), we know that

$$
\operatorname{TRC}(T)=\left\{\begin{array}{cc}
T R C_{4}(T), \quad \text { if } N \leq T, \quad \text { (a) } \\
T R C_{1}(T), \quad \text { if } W / D \leq T<N, \quad \text { (b) } \\
T R C_{5}(T), \quad \text { if } M \leq T<W / D, \quad \text { (c) } \\
T R C_{3}(T), \quad \text { if } 0<T<M \quad \text { (d) }
\end{array}\right.
$$

From Eq. (14) and (16), find $T_{i}^{*}$ such that $T R C_{i}^{\prime}\left(T_{i}^{*}\right)=0$ for each $i=4,5$. Then, we can obtain

$$
T_{4}^{*}=\sqrt{\frac{2 A+D N^{2}\left(c I_{k}-s I_{e}\right)}{D\left(h+c I_{k}\right)}}
$$

and

$$
T_{5}^{*}=\sqrt{\frac{2 A+c D M^{2}\left(I_{k}+I_{p}\right)}{D\left[h+s I_{e}-c\left(I_{k}+I_{p}\right)\right]}} \text { if }\left(h+s I_{e}\right)>c\left(I_{k}+I_{p}\right) .
$$

In similar fashion, we can obtain following results:

$N \leq T_{4}^{*}$, if and only if $-2 A+D N^{2}\left(h+s I_{e}\right) \leq 0$,
$T_{1}^{*}<N$, if and only if $-2 A+D N^{2}\left(h+s I_{e}\right)>0$, and

$W / D \leq T_{1}^{*}$, if and only if $-2 A+\frac{W^{2}}{D}\left(h+s I_{e}\right) \leq 0$,

$T_{5}^{*}<W / D$, if and only if $-2 A+\frac{W^{2}}{D}\left[h+s I_{e}-c\left(I_{k}+I_{p}\right)\right]-c D M^{2}\left(I_{k}+I_{p}\right)>0$,

and

$M \leq T_{5}^{*}$, if and only if $-2 A-2 D M^{2} c\left(I_{k}+I_{p}\right)+D M^{2}\left(h+s I_{e}\right) \leq 0$,

$T_{3}^{*}<M$, if and only if $-2 A+D M^{2}\left(h+s I_{e}\right)>0$.

Furthermore, to simplify, we let

$$
\begin{aligned}
& \Delta_{1}=-2 A+D M^{2}\left(h+s I_{e}\right), \\
& \Delta_{2}=-2 A+\frac{W^{2}}{D}\left(h+s I_{e}\right), \\
& \Delta_{3}=-2 A+D N^{2}\left(h+s I_{e}\right), \\
& \Delta_{4}=-2 A-c D M^{2}\left(I_{k}+I_{p}\right)+\frac{W^{2}}{D}\left[\left(h+s I_{e}\right)-c\left(I_{k}+I_{p}\right)\right], \\
& \Delta_{5}=-2 A-2 c D M^{2}\left(I_{k}+I_{p}\right)+D M^{2}\left(h+s I_{e}\right) .
\end{aligned}
$$

We observe that $\Delta_{3} \geq \Delta_{2}>\Delta_{1}$ and $\Delta_{4}>\Delta_{5}$. In addition, we know that $T R C_{5}(T) \geq T R C_{1}(T)$ for all $T>0$ from Eq. (2) and Eq. (13). From above arguments, we can summarize the above results in Theorem 2. 
Theorem2. Suppose that $\left(h+s I_{e}\right)>c\left(I_{k}+I_{p}\right)$ and $M<W / D \leq N$, then

(A) $\Delta_{1} \geq 0, \Delta_{2} \geq 0, \Delta_{3} \geq 0, \Delta_{4} \geq 0$ and $\Delta_{5} \geq 0$, then $\operatorname{TRC}\left(T^{*}\right)=T R C_{3}\left(T_{3}^{*}\right)$ and $T^{*}=T_{3}^{*}$.

(B) $\Delta_{1}<0, \Delta_{2} \geq 0, \Delta_{3} \geq 0, \Delta_{4} \geq 0$ and $\Delta_{5} \geq 0$, then $T R C\left(T^{*}\right)=T R C(M)$ and $T^{*}=M$.

(C) $\Delta_{1}<0, \Delta_{2}<0, \Delta_{3} \geq 0, \Delta_{4} \geq 0$ and $\Delta_{5} \geq 0$, then $\operatorname{TRC}\left(T^{*}\right)=T R C_{1}\left(T_{1}^{*}\right)$ and $T^{*}=T_{1}^{*}$.

(D) $\Delta_{1}<0, \Delta_{2}<0, \Delta_{3}<0, \Delta_{4} \geq 0$ and $\Delta_{5} \geq 0$, then $\operatorname{TRC}\left(T^{*}\right)=T R C_{4}\left(T_{4}^{*}\right)$ and $T^{*}=T_{4}^{*}$.

(E) $\Delta_{1} \geq 0, \Delta_{2} \geq 0, \Delta_{3} \geq 0, \Delta_{4} \geq 0$ and $\Delta_{5}<0$, then $\operatorname{TRC}\left(T^{*}\right)=\min \left\{T R C_{3}\left(T_{3}^{*}\right), T R C_{5}\left(T_{5}^{*}\right)\right\}$ hence $T^{*}$ is $T_{3}^{*}$ or $T_{5}^{*}$ whichever has the least cost.

(F) $\Delta_{1}<0, \Delta_{2} \geq 0, \Delta_{3} \geq 0, \Delta_{4} \geq 0$ and $\Delta_{5}<0$, then $\operatorname{TRC}\left(T^{*}\right)=T R C_{5}\left(T_{5}^{*}\right)$ and $T^{*}=T_{5}^{*}$.

(G) $\Delta_{1}<0, \Delta_{2}<0, \Delta_{3} \geq 0, \Delta_{4} \geq 0$ and $\Delta_{5}<0$, then $T R C\left(T^{*}\right)=\min \left\{T R C_{1}\left(T_{1}^{*}\right), T R C_{5}\left(T_{5}^{*}\right)\right\}$ hence $T^{*}$ is $T_{1}^{*}$ or $T_{5}^{*}$ whichever has the least cost.

(H) $\Delta_{1}<0, \Delta_{2}<0, \Delta_{3}<0, \Delta_{4} \geq 0$ and $\Delta_{5}<0$, then $T R C\left(T^{*}\right)=\min \left\{T R C_{4}\left(T_{4}^{*}\right), T R C_{5}\left(T_{5}^{*}\right)\right\}$ hence, $T^{*}$ is $T_{4}^{*}$ or $T_{5}^{*}$ whichever has the least cost.

(I) $\Delta_{1} \geq 0, \Delta_{2} \geq 0, \Delta_{3} \geq 0, \Delta_{4}<0$ and $\Delta_{5}<0$, then $\operatorname{TRC}\left(T^{*}\right)=T R C_{3}\left(T_{3}^{*}\right)$ and $T^{*}=T_{3}^{*}$.

(J) $\Delta_{1}<0, \Delta_{2} \geq 0, \Delta_{3} \geq 0, \Delta_{4}<0$ and $\Delta_{5}<0$, then TRC $\left(T^{*}\right)=\operatorname{TRC}(W / D)$ and $T^{*}=W / D$.

(K) $\Delta_{1}<0, \Delta_{2}<0, \Delta_{3} \geq 0, \Delta_{4}<0$ and $\Delta_{5}<0$, then $\operatorname{TRC}\left(T^{*}\right)=T R C_{1}\left(T_{1}^{*}\right)$ and $T^{*}=T_{1}^{*}$.

(L) $\Delta_{1}<0, \Delta_{2}<0, \Delta_{3}<0, \Delta_{4}<0$ and $\Delta_{5}<0$, then $\operatorname{TRC}\left(T^{*}\right)=T R C_{4}\left(T_{4}^{*}\right)$ and $T^{*}=T_{4}^{*}$.

\subsection{Decision rule of the optimal cycle time when $N<W / D$}

If $N<W / D$, from Eqs. (18(a)-(b)), we know that

$$
\operatorname{TRC}(T)=\left\{\begin{array}{cc}
T R C_{4}(T), & \text { if } W / D \leq T, \\
T R C_{6}(T), & \text { if } N \leq T<W / D, \\
T R C_{5}(T), & \text { if } 0<T<N .
\end{array}\right.
$$

From Eq. (20), find $T_{6}^{*}$ such that $T R C_{6}^{\prime}\left(T_{6}^{*}\right)=0$, we can obtain

$$
T_{6}^{*}=\sqrt{\frac{2 A+D N^{2}\left(c I_{k}-s I_{e}\right)+c D\left(I_{k}+I_{p}\right)(N-M)^{2}}{D\left(h+c I_{k}\right)}} .
$$

In a similar fashion, we can obtain following results:

$W / D \leq T_{4}^{*}$, if and only if $-2 A+\frac{W^{2}}{D}\left(h+c I_{k}\right)-D N^{2}\left(c I_{k}-s I_{e}\right) \leq 0$,

$T_{6}^{*}<W / D$, if and only if $-2 A+\frac{W^{2}}{D}\left(h+c I_{k}\right)-D N^{2}\left(c I_{k}-s I_{e}\right)-c D\left(I_{k}+I_{p}\right)(N-M)^{2}>0$, and

$N \leq T_{6}^{*}$, if and only if $-2 A+D N^{2}\left(h+c I_{k}\right)-D N^{2}\left(c I_{k}-s I_{e}\right)-c D\left(I_{k}+I_{p}\right)(N-M)^{2} \leq 0$,

$T_{5}^{*} \leq N$, if and only if $-2 A+D N^{2}\left[h+s I_{e}-c\left(I_{k}+I_{p}\right)\right]-c D M^{2}\left(I_{k}+I_{p}\right) \geq 0$.

Furthermore, to simplify, we let

$$
\Delta_{6}=-2 A+\frac{W^{2}}{D}\left(h+c I_{k}\right)-D N^{2}\left(c I_{k}-s I_{e}\right),
$$




$$
\begin{aligned}
& \Delta_{7}=-2 A+\frac{W^{2}}{D}\left(h+c I_{k}\right)-D N^{2}\left(c I_{k}-s I_{e}\right)-c D\left(I_{k}+I_{p}\right)(N-M)^{2}, \\
& \Delta_{8}=-2 A+D N^{2}\left(h+c I_{k}\right)-D N^{2}\left(c I_{k}-s I_{e}\right)-c D\left(I_{k}+I_{p}\right)(N-M)^{2}, \\
& \Delta_{9}=-2 A+D N^{2}\left[h+s I_{e}-c\left(I_{k}+I_{p}\right)\right]-c D M^{2}\left(I_{k}+I_{p}\right) .
\end{aligned}
$$

We observe that, $\Delta_{6} \geq \Delta_{7}$ and $\Delta_{7}>\Delta_{8}>\Delta_{9}$. In addition, we know that, $\operatorname{TRC}_{5}(N)=T R C_{6}(N)$ and $T R C_{6}(W / D)>T R C_{4}(W / D)$ for all $T>0$. From above arguments, we can summarize the above results in Theorem 3.

Theorem3. Suppose that $\left(h+s I_{e}\right)>c\left(I_{k}+I_{p}\right)$ and $N<W / D$, then

(A) $\Delta_{6} \geq 0, \Delta_{7} \geq 0, \Delta_{8} \geq 0$ and $\Delta_{9} \geq 0$, then $T R C\left(T^{*}\right)=T R C_{5}\left(T_{5}^{*}\right)$ and $T^{*}=T_{5}^{*}$,

(B) $\Delta_{6} \geq 0, \Delta_{7} \geq 0, \Delta_{8} \geq 0$ and $\Delta_{9}<0$, then $T R C\left(T^{*}\right)=\operatorname{TRC}(N)$ and $T^{*}=N$,

(C) $\Delta_{6} \geq 0, \Delta_{7} \geq 0, \Delta_{8}<0$ and $\Delta_{9}<0$, then $T R C\left(T^{*}\right)=T R C_{6}\left(T_{6}^{*}\right)$ and $T^{*}=T_{6}^{*}$,

(D) $\Delta_{6} \geq 0, \Delta_{7}<0, \Delta_{8}<0$ and $\Delta_{9}<0$, then $T R C\left(T^{*}\right)=T R C(W / D)$ and $T^{*}=W / D$,

(E) $\Delta_{6}<0, \Delta_{7}<0, \Delta_{8}<0$ and $\Delta_{9}<0$, then $T R C\left(T^{*}\right)=T R C_{4}\left(T_{4}^{*}\right)$ and $T^{*}=T_{4}^{*}$.

\section{Numerical examples}

In this section, the current studies make accessible the following numerical examples to illustrate the theoretical results as reported in Section 3. For dexterity, the values of the parameters are preferred randomly. The optimal cycle time and optimal order quantity for different parameters of $M(0.06,0.05$, and 0.04$), W(50,100$, and 200) and $s(15,30$, and 60) are shown in Table 1.

Let $A=\$ 50 /$ order, $D=1000$ units/year, $c=10 /$ per unit, $h=\$ 5 /$ unit/year, $I_{k}=\$ 0.1 / \$ /$ year, $I_{p}=\$ 0.04$ /\$/year, $I_{e}=\$ 0.07 / \$ /$ year and $N=0.12$ year.

The following deductions can be made based on Table 1.

(1) For fixed $W$ and $s$, increasing the value of $M$ will effect in a significant increase in the value of the optimal order quantity and a significant reduce in the worth of the annual total relevant costs as the retailer's order quantity is smaller and only the flexible policy to impediment payment is permitted. For example, when $W=100, s=15$ and an increases from 0.04 to 0.05 , the optimal order size will increase $28.63 \%((128.634-100) / 100)$ and the annual total related costs will decrease $12.04 \%$ $((741.100-651.803) / 741.100)$. It implies that the retailer will order a bigger quantity since the retailer can get pleasure from greater benefits under FTCP when the length of the fixed point $M$ in the permissible delay period is increasing. So the supplier can use the policy of increasing $M$ to stimulate the demands from the retailer.

(2) For fixed $M$ and $s$, increasing the assessment of $W$ will result in a significant shrink in the value of the optimal order quantity and a significant increase in the value of the annual total relevant costs. For example, when $M=0.05, s=30$ and $W$ increases from 100 to 200, the optimal order quantity will reduce 15.19\% $((118.678-100.648) / 118.678)$ and the annual total relevant costs will augment $5.88 \%((625.396-590.615) / 590.615)$. It implies that the seller will not order a quantity as large as the minimum arrange quantity as required to acquire fully permissible delay in payments. Hence, the outcome of stimulating the demands from the retailer turns unenthusiastic when the supplier adopts a policy to increase the value of $W$.

(3) Last, for fixed $M$ and $W$, increasing the cost of $s$ will consequence in a significant cut in the value of the optimal order quantity and a significant lessen in the value of the annual total relevant cost. For 
example, when $M=0.04, W=50$ and $s$ increases from 15 to 60 , the optimal order amount will reduce $18.90 \%((128.565-104.257) / 128.565)$ and the annual total related costs will cut $30.16 \%$ ((651.817-455.166)/651.817). This consequence implies that the retailer will order a smaller quantity to take pleasure in the benefits of either the fully or the full permissible impediment in payments under the flexible trade credit policy more frequently in the occurrence of an increased unit selling price.

\section{Table 1}

Optimal solutions under dissimilar parametric values

\begin{tabular}{|c|c|c|c|c|c|c|c|}
\hline$M$ & $W$ & $S$ & Judgments & $T^{*}$ & $Q^{*}$ & $\operatorname{TRC}\left(T^{*}\right)$ & Theorems \\
\hline \multirow[t]{9}{*}{0.06} & 50 & 15 & $\Delta_{1}<0, \Delta_{2}<0$ & $T_{1}^{*}=0.128565$ & 128.565 & 651.817 & $1-(A)$ \\
\hline & & 30 & $\Delta_{1}<0, \Delta_{2}<0$ & $T_{1}^{*}=0.118678$ & 118.678 & 590.615 & $1-(A)$ \\
\hline & & 60 & $\Delta_{1}<0, \Delta_{2}<0$ & $T_{1}^{*}=0.104257$ & 104.257 & 455.166 & $1-(A)$ \\
\hline & 100 & 15 & $\Delta_{1}<0, \Delta_{2}<0, \Delta_{3}<0, \Delta_{4}<0, \Delta_{5}<0$ & $T_{4}^{*}=0.128634$ & 128.634 & 651.803 & $2-(L)$ \\
\hline & & 30 & $\Delta_{1}<0, \Delta_{2}<0, \Delta_{3}>0, \Delta_{4}<0, \Delta_{5}<0$ & $T_{1}^{*}=0.118678$ & 118.678 & 590.615 & $2-(K)$ \\
\hline & & 60 & $\Delta_{1}<0, \Delta_{2}<0, \Delta_{3}>0, \Delta_{4}<0, \Delta_{5}<0$ & $T_{1}^{*}=0.104257$ & 104.257 & 455.166 & $2-(K)$ \\
\hline & 200 & 15 & $\Delta_{6}>0, \Delta_{7}>0, \Delta_{8}<0, \Delta_{9}<0$ & $T_{6}^{*}=0.131859$ & 131.859 & 675.246 & $3-(C)$ \\
\hline & & 30 & $\Delta_{6}>0, \Delta_{7}>0, \Delta_{8}<0, \Delta_{9}<0$ & $T_{6}^{*}=0.121929$ & 121.929 & 616.002 & $3-(C)$ \\
\hline & & 60 & $\Delta_{6}>0, \Delta_{7}>0, \Delta_{8}>0, \Delta_{9}<0$ & $N=0.12$ & 120 & 490.167 & $3-(B)$ \\
\hline \multirow[t]{9}{*}{0.05} & 50 & 15 & $\Delta_{1}<0, \Delta_{2}<0$ & $T_{1}^{*}=0.128565$ & 128.565 & 651.817 & $1-(A)$ \\
\hline & & 30 & $\Delta_{1}<0, \Delta_{2}<0$ & $T_{1}^{*}=0.118678$ & 118.678 & 590.615 & $1-(A)$ \\
\hline & & 60 & $\Delta_{1}<0, \Delta_{2}<0$ & $T_{1}^{*}=0.104257$ & 104.257 & 455.166 & $1-(A)$ \\
\hline & 100 & 15 & $\Delta_{1}<0, \Delta_{2}<0, \Delta_{3}<0, \Delta_{4}<0, \Delta_{5}<0$ & $T_{4}^{*}=0.128634$ & 128.634 & 651.803 & $2-(L)$ \\
\hline & & 30 & $\Delta_{1}<0, \Delta_{2}<0, \Delta_{3}>0, \Delta_{4}<0, \Delta_{5}<0$ & $T_{1}^{*}=0.118678$ & 118.678 & 590.615 & $2-(K)$ \\
\hline & & 60 & $\Delta_{1}<0, \Delta_{2}<0, \Delta_{3}>0, \Delta_{4}<0, \Delta_{5}<0$ & $T_{1}^{*}=0.104257$ & 104.257 & 455.166 & $2-(K)$ \\
\hline & 200 & 15 & $\Delta_{6}>0, \Delta_{7}>0, \Delta_{8}<0, \Delta_{9}<0$ & $T_{6}^{*}=0.131859$ & 131.859 & 675.246 & $3-(C)$ \\
\hline & & 30 & $\Delta_{6}>0, \Delta_{7}>0, \Delta_{8}<0, \Delta_{9}<0$ & $T_{6}^{*}=0.100648$ & 100.648 & 625.396 & $3-(C)$ \\
\hline & & 60 & $\Delta_{6}>0, \Delta_{7}>0, \Delta_{8}>0, \Delta_{9}<0$ & $N=0.12$ & 120 & 490.167 & $3-(B)$ \\
\hline \multirow[t]{9}{*}{0.04} & 50 & 15 & $\Delta_{1}<0, \Delta_{2}<0, \Delta_{3}>0, \Delta_{4}<0, \Delta_{5}<0$ & $T_{1}^{*}=0.128565$ & 128.565 & 651.817 & $2-(K)$ \\
\hline & & 30 & $\Delta_{1}<0, \Delta_{2}<0, \Delta_{3}>0, \Delta_{4}<0, \Delta_{5}<0$ & $T_{1}^{*}=0.118678$ & 118.678 & 590.615 & $2-(K)$ \\
\hline & & 60 & $\Delta_{1}<0, \Delta_{2}<0, \Delta_{3}>0, \Delta_{4}<0, \Delta_{5}<0$ & $T_{1}^{*}=0.104257$ & 104.257 & 455.166 & $2-(K)$ \\
\hline & 100 & 15 & $\Delta_{1}<0, \Delta_{2}>0, \Delta_{3}>0, \Delta_{4}<0, \Delta_{5}<0$ & $T^{*}=0.1$ & 100 & 741.100 & $2-(J)$ \\
\hline & & 30 & $\Delta_{1}<0, \Delta_{2}>0, \Delta_{3}>0, \Delta_{4}>0, \Delta_{5}<0$ & $T_{5}^{*}=0.133928$ & 133.928 & 629.095 & $2-(F)$ \\
\hline & & 60 & $\Delta_{1}<0, \Delta_{2}>0, \Delta_{3}>0, \Delta_{4}>0, \Delta_{5}<0$ & $T_{5}^{*}=0.133928$ & 133.928 & 629.095 & $2-(F)$ \\
\hline & 200 & 15 & $\Delta_{6}>0, \Delta_{7}>0, \Delta_{8}>0, \Delta_{9}<0$ & $N=0.12$ & 120 & 699 & $3-(B)$ \\
\hline & & 30 & $\Delta_{6}>0, \Delta_{7}>0, \Delta_{8}>0, \Delta_{9}<0$ & $N=0.12$ & 120 & 636 & $3-(B)$ \\
\hline & & 60 & $\Delta_{6}>0, \Delta_{7}>0, \Delta_{8}>0, \Delta_{9}<0$ & $N=0.12$ & 120 & 510 & $3-(B)$ \\
\hline
\end{tabular}

\section{A special case}

The value $W=0$ and $s=c$ mean that the broker offers the retailer permissible impediment in payments sovereign of the order quantity. The value $M=N$ that is $I_{p}$ means that the supplier offers the retailer fully permissible delay in payment. Therefore, when $W=0$ and $M=N$, Eqs. (11(a)-(d)) will reduce to 


$$
\operatorname{TRC}(T)=\left\{\begin{array}{ccc}
T R C_{4}(T), & \text { if } & M \leq T(a) \\
T R C_{1}(T), & \text { if } & 0<T \leq M(b)
\end{array}\right.
$$

Eqs. (37(a)-(b)) will be consistent with Eq. (1) and Eq. (4) in Goyal (1985), respectively. Hence, Goyal (1985) will be a special case of this paper. From Eq. (27), we know $\Delta_{1}=-2 A+D M^{2}\left(h+s I_{e}\right)$. If we let $\Delta=-2 A+D M^{2}\left(h+s I_{e}\right)$, Theorem 2 can be modified as follows:

\section{Theorem4.}

(A) If $\Delta>0$, then $T^{*}=T_{1}^{*}$.

(B) If $\Delta<0$, then $T^{*}=T_{4}^{*}$.

(C) If $\Delta=0$, then $T^{*}=T_{1}^{*}=T_{4}^{*}=M$.

Theorem 4 has been discussed in Chung (1998). Hence, Theorem 1 in Chung (1998) is a special case of Theorem 2 of the current study.

\section{Conclusions}

As, we are well known by our experience that supplier offers the permissible delay in payments to the retailer in order to stimulate his demand. So, the assumption in previously published results that the fully permissible delay in payments is permitted under a sufficient quantity is practical. On the other hand, the permissible delay in payments will not be permitted when the order quantity is smaller than a predetermined quantity obviously is an extreme case.

In this paper, the proposed model allows the supplier to offer an alternative policy, i.e., flexible trade credit policy, to overcome the extreme case when the retailer's order quantity is not large enough to get the fully permissible delay in payment. Viewed from such prospective, I formed the inventory system to take care of the following states: The retailer will under fully permissible delay in payment if the retailer orders a large quantity; Otherwise, the retailer will obtain full permissible delay in payment with paying extra interest only for some portion of the trade credit period by the end of the delay period.

In addition, we established three effective and easy-to-use theorems to help retailers to find out their optimal replenishment policy. The following insights can be concluded as:

(1) A higher length of the fixed point in the delay period brings about a larger order quantity and smaller annual total relevant costs;

(2) A higher amount of the offered minimum order quantity as required to obtain fully permissible delay in payments brings a force of ordering small quantity with large annual total relevant costs;

(3) A higher value of unit selling price also brings a tendency to order undersized quantity and to use the benefits of less annual total relevant costs.

Therefore, from the viewpoint of supplier's marketing policy, the supplier can use the length of the fixed point in the delay period to control more agilely the effects of stimulating demands from retailers. For example, the supplier can offer the large length of the fixed point in the delay period to attract the large orders. On the other hand, the supplier can use the smaller length of the fixed point in the delay period to reduce the order size. 
The proposed model can be extended in several ways ahead. For instance, we may generalize the model to allow for shortages, deteriorating items, probabilistic demand, time value of money, finite time horizon and finite replenishment rate.

\section{References}

Abad, P.L., \& Jaggi, C.K. (2003). A joint approach for setting unit price and the length of the credit period for a seller when end demand is price sensitive. International Journal of Production Economics, 83(2), 115-122.

Aggarwal, S.P., \& Jaggi, C.K. (1995). Ordering policies of deteriorating items under permissible delay in payments. Journal of the Operational Research Society, 46(5), 658-662.

Chung, K.J. (1998). A theorem on the determination of economic order quantity under conditions of permissible delay in payments. Computers and Operations Research, 25(1), 49-52.

Chung, K.J., \& Huang, Y.F. (2003). The optimal cycle time for EPQ inventory model under permissible delay in payments. International Journal of Production Economics, 84(3), 307-318.

Chang, C.T. (2004). An EOQ model with deteriorating items under inflation when supplier credits linked to order quantity. International Journal of Production Economics, 88(3), 307-316.

Chung, K.J., \& Liao, J.J. (2004). Lot-sizing decisions under trade credit depending on the ordering quantity. Computers and Operations Research, 31(6), 909-928.

Chung, K.J., Goyal, S.K., \& Huang, Y.F. (2005). The optimal inventory policies under permissible delay in payment depending on the ordering quantity. International Journal of Production Economics, 95(2), 203-213.

Chang, H.C., Ho, C.H., \& Ouyang, C.H.S. (2009). The optimal pricing and ordering policy for an integral inventory model when trade credit linked to order quantity. Applied Mathematical Modeling, 33(7), 2978-2991.

Chen, L.H., \& Kang, F.S. (2010). Integrated inventory models considering the two-level trade credit policy and a price-negotiation scheme. European Journal of Operational Research, 205(1), 47-58.

Chung, K.J., \& Liao, J.J. (2011). The simplified solution algorithm for an integrated supplier-buyer inventory model with two-part trade credit in a supply chain system. European Journal of Operational Research, 213(1), 156-165.

Goyal, S.K. (1985). Economic order quantity under conditions of permissible delay in payments. Journal of the Operational Research Society, 36(4), 335-338.

Goyal, S.K., Teng, J.T., \& Chang, C.T. (2007). Optimal ordering policies when the supplier provides a progressive interest scheme. European Journal of Operational Research, 179(2), 404-413.

Huang, Y.F. (2003). Optimal retailer's ordering policies in the EOQ model under trade credit financing. Journal of the Operational Research Society, 54(9), 1011-1015.

Huang, Y.F. (2004) .Optimal retailer's replenishment policy for the EPQ model under supplier's trade credit policy. Production Planning and Control, 15(1), 27-33.

Huang, Y.F., \& Chung, K.J. (2003). Optimal replenishment and payment policies in the EOQ model under cash discount and trade credit. Asia-Pacific Journal of Operational Research, 20(2), 177-190.

Huang, Y.F. (2007). Economic order quantity under conditionally permissible delay in payments.European Journal of Operational Research, 176(2), 911-924.

Ho, C.H., Ouyang, L.Y., \& Su, C.H. (2008). Optimal pricing, shipment and payment policy for an integrated supplier-buyer inventory model with two-part trade credit. European Journal of Operational Research, 187(2), 496-510.

Huang, C.K, Tsai, D.M., Wu, J.C., \& Chung, K.J. (2010). An integrated vendor-buyer inventory model with order-processing cost reduction and permissible delay in payments. European Journal of Operational Research, 202(2), 473-478.

Jamal, A.M.M., Sarker, B.R., \& Wang, S. (2000). Optimal payment time for a retailer under permitted delay of payment by the wholesaler. International Journal of Production Economics, 66(1), 59-66. 
Jaggi, C.K., Goyal, S.K., \& Goel, S.K. (2008). Retailer's optimal replenishment decisions with creditlinked demand under permissible delay in payments. European Journal of Operational Research, 190(1), 130-135.

Krreng, V.B., \& Tan, S.J. (2010). The optimal replenishment decisions under two levels of trade credit policy depending on the order quantity. Expert Systems with Applications, 37(7), 5514-5522.

Liao, J.J., \& Chung, J.K. (2009). The optimal ordering policy of the EOQ model under trade credit depending on the ordering quantity from the DCF approach. European Journal of Operational Research, 196, 563-568.

Ouyang, L.Y., Teng, J.T., Goyal, S.K., \& Yang, C.T. (2009). An economic order quantity model for deteriorating items with partially permissible delay in payments linked to order quantity. European Journal of Operational Research, 194(2), 418-431.

Sana, S.S, \& Chaudhuri, K.S. (2008). A deterministic EOQ model with delays in payments and pricediscount offers. European Journal of Operational Research, 184(2), 509-533.

Seifert, D., Seifert, R. W., \& Sieke, M. P. (2013). A review of trade credit literature: Opportunities for research in operations. European Journal of Operational Research, 231(2), 245-256.

Teng, J.T. (2002). On the economic order quantity under conditions of permissible delay in payments. Journal of the Operational Research Society, 53, 915-918.

Zhou, Y.W., Zhong, Y., \& Li, J. (2012). An uncooperative order model for items with trade credit, inventory-dependent demand and limited displayed-shelf space. European Journal of Operational Research, 223(1), 76-85.

Zhou,Y.W., Zhong,Y.G., \& Wahab, M.I.M. (2013). How to make the replenishment and payment strategy under flexible two-part trade credit. Computers and Operations Research, 40(5), 1328-1338. 